\title{
Occurrence of epidermal growth factor receptors in benign and malignant ovarian tumors and normal ovarian tissues: an immunohistochemical study*
}

\author{
S. C. Henzen-Logmans ${ }^{1}$, M.E.L. van der Burg ${ }^{2}$, J. A. Foekens ${ }^{3}$, P. M. J. J. Berns ${ }^{3}$, R. Brussée ${ }^{3}$, \\ J.H. Fieret ${ }^{1}$, J. G. M. Klijn ${ }^{2}$, S. Chadha ${ }^{4}$, and C.J. Rodenburg ${ }^{2}$ \\ 1 Department of Pathology, ${ }^{2}$ Department of Medical Oncology, ${ }^{3}$ Division of Endocrine Oncology, \\ Dr. Daniel den Hoed Cancer Center, Rotterdam, The Netherlands \\ 4 Department of Pathology, Erasmus University, Rotterdam, The Netherlands
}

Received 12 August 1991/Accepted 19 November 1991

\begin{abstract}
Summary. Epidermal growth factor receptor (EGF-R) was studied with monoclonal antibody $2 \mathrm{E} 9$ on 50 ovarian tumors of various histological types and 10 non-tumorous ovarian tissues by immunohistochemistry. Enhanced expression was observed in $26 / 50(52 \%)$ of the tumors. Only 25 out of 46 epithelial tumors $(54 \%)$ showed positivity in epithelial tumor cells. Staining was cytoplasmic in all cases. No correlation was established between EGF-R expression and the histological type of the epithelial tumor. Apart from EGF-R expression in tumor cells, low immunoreactivity was also observed in stromal and endothelial cells in both normal and tumorous ovarian tissues. Furthermore in 8/9 specimens containing necrotic areas, EGF-R was noticed in these areas as well. Both of the latter observations may have impact on the evaluation of the prognostic value of EGF-R activity in tumors, when based on EGF-R measurements using biochemical binding studies. We therefore recommend that EGF-R is measured with both methods in studies regarding its clinical value.
\end{abstract}

Key words: EGF receptors - Immunohistochemistry Ovarian carcinomas

\section{Introduction}

Although the management of patients with advanced ovarian cancer has improved, the prognosis remains poor (Neyt et al. 1985): the 10-year survival rate of patients in Figo stages III and IV following cisplatin-containing chemotherapy is only $20 \%$ (Sutton et al. 1989). Therefore, new treatment modalities are urgently needed. In the last

\footnotetext{
* Supported by grant DDHK 90-05 from the Dutch Cancer Society "Koningin Wilhelmina Fonds"

Offprint requests to: S.C. Henzen-Logmans, Department of Pathology, Dr. Daniel den Hoed Cancer Center, Groene Hilledijk 301, 3075 EA Rotterdam, The Netherlands
}

few years much attention has been focussed on the role of growth factors and their receptors in the development and biology of cancer (Greig et al. 1988). Evidence exists that the presence of growth factor receptors on tumor cells may be of importance with respect to the clinical outcome of several malignancies (Greig et a. 1988). The prognostic value of epidermal growth factor receptors (EGF-R) is especially under discussion in breast cancer (Sainsbury et al. 1987; Foekens et al. 1989; Nicholson et al. 1989).

In ovarian cancer, data on EGF or their receptors are limited. Bauknecht et al. (1989a,b) and Battaglia et al. (1989) reported EFG-R positivity in $36 \%(n=101), 45 \%$ $(n=141)$ and $75 \%(n=24)$ of patients respectively. What is important is that the presence of these receptors appeared to be of prognostic significance in the studies of Bauknecht et al. (1989a,b). These studies with respect to EGF-R in ovarian (cancer) tissues were performed using biochemical binding assays on membrane homogenates only. Since heterogeneity in the distribution of EGF-R within an individual tumor cannot be determined by biochemical methods we have focussed on the immunohistochemical examination both of different histological subtypes of ovarian cancer and of normal ovarian tissues for the incidence and distribution of EGF-R.

\section{Materials and methods}

Fifty tumors and 10 non-tumorous ovaries were analyzed. Tumors were classified according to the WHO classification 1973 (Serov and Scully 1973). Fifteen patients (mean age 57 years) had a serous adenocarcinoma, 6 patients (mean age 50 years) had a mucinous adenocarcinoma, 11 patients (mean age 53 years) had an endometroid carcinoma, 4 patients (mean age 55 years) had a clear-cell carcinoma, 3 patients (mean age 50 years) had a poorly differentiated carcinoma, 3 patients (mean age 47 years) had borderline malignant epithelial tumors ( 1 serous, 2 mucinous) and 4 patients (mean age 65 years) benign epithelial tumors ( 2 serous, 1 mucinous cystadenoma, and 1 adenofibroma). Apart from these epithelial tumors 4 patients (mean age 41 years) had non-epithelial ovarian tumors [3 
sex cord tumors ( 1 granulosa cell and 2 thecoma) and 1 germ-cell tumor (immature teratoma)].

Representative tissue samples were snap-frozen in liquid nitrogen and stored at $-70^{\circ} \mathrm{C}$ until use. Serial sections were cut $4 \mu \mathrm{m}$ thick. These were air-dried and fixed in acetone for $10 \mathrm{~min}$, after which the indirect immunoperoxidase technique was used. Briefly, after rinsing for $15 \mathrm{~min}$ in phosphate-buffered saline (PBS), in the first step, monoclonal antibody 2E9 (Defize et al. 1987, 1989) IgG1 [Anti-(protein core)low-affinity EFG-R, extracellular domain; generously provided by Dr. L.H.H. Defize, Hubrecht Laboratory Utrecht, The Netherlands] was applied on sections for $24 \mathrm{~h}$ at $4^{\circ} \mathrm{C}$ $(50 \mu \mathrm{g} / \mathrm{ml})$. After rinsing with PBS for $15 \mathrm{~min}$, the second antibody, horseradish-peroxidase-conjugated rabbit anti-(mouse IgG) (Dako) (dilution 1:160), was applied for $30 \mathrm{~min}$. After washing, peroxidase staining with DAB-H202 and rinsing in PBS, sections were counterstained with haemalum and mounted with malinol. All immunoreagents were diluted in PBS containing $2 \%$ normal human serum and normal rabbit serum. Control sections consisted of known positive and negative specimens identified by ligand-binding assay. In addition, in one negative control section the first-layer antibody was changed to PBS or non-immune ascites fluid.

-Intensity of immunohistochemical staining was subjectively estimated as negative $(0)$, very weakly \pm or weakly positive + , moderately positive ++ , or strongly positive +++ . The percentages of stained tumor cells were noted in categories of $5 \%-25 \%, 26 \%$ $50 \%, 51 \%-75 \%$, and $>75 \%$.

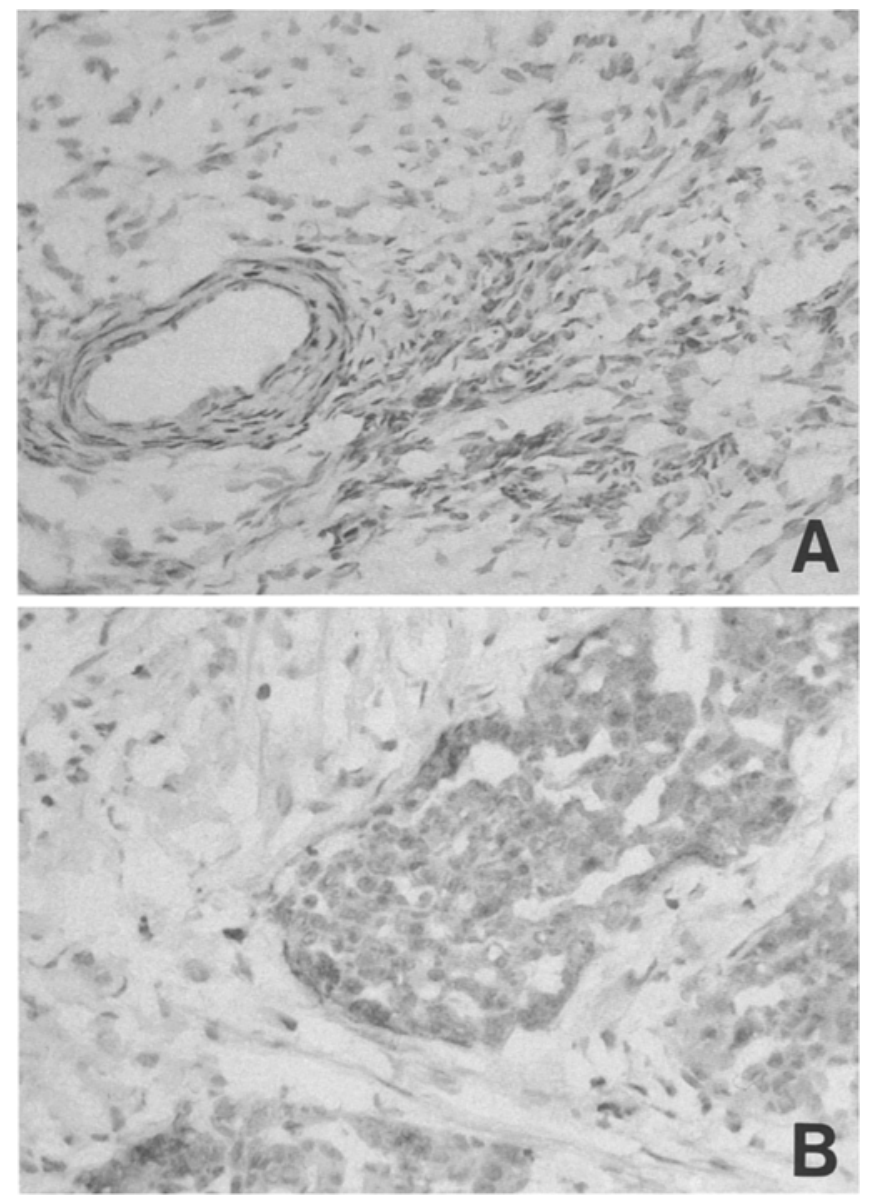

Fig. 1. A Detail of normal ovarian tissue: a very weak staining of stromal and endothelial cells (haemalum counterstained, 250×). B Detail of poorly differentiated carcinoma. A strong staining is noticed in tumor cells. Stromal cells do stain very weakly (haemalum counterstained, $250 \times$ )
Table 1. Expression of epidermal growth factor receptor (EGF-R) in ovarian tumors

\begin{tabular}{|c|c|c|}
\hline \multirow[t]{2}{*}{ Tissue type } & EGF-R ${ }^{a}$ & \multirow{2}{*}{$\begin{array}{l}\text { Total no. } \\
\text { of cases }\end{array}$} \\
\hline & $=$ & \\
\hline
\end{tabular}

Epithelial ovarian tumors

Serous carcinoma

Mucinous carcinoma

Endometrioid carcinoma

Clear-cell carcinoma

Poorly differentiated carcinomas

Borderline serous

Borderline mucinous

Benign serous

Benign mucinous

Adenofibroma

Other ovarian tumors

Sex cord tumors

Granulosa cell

Thecoma

Germ-cell tumors

Immature teratoma

Total

$\begin{array}{rrr}6 & 9 & 15 \\ 1 & 5 & 6 \\ 5 & 6 & 11 \\ 3 & 1 & 4 \\ 2 & 1 & 3 \\ & & \\ 1 & 0 & 1 \\ 0 & 2 & 2 \\ 1 & 1 & 2 \\ 1 & 0 & 1 \\ 1 & 0 & 1\end{array}$

5

6

4

3

1

2

2

1

a $\mathrm{EGF-R}=$, not enhanced in tumor cells when compared to intrinsic stromal component; EGF-R $\uparrow$, enhanced expression of EGF-R in tumor cells when compared to intrinsic stromal component

\section{Results}

In non-tumorous ovaries $(n=10)$, apart from surface epithelial cells, spindle-shaped stromal cells and endothelial cells of the vessel walls within the cortical or medullary area often $(9 / 10)$ showed very weak $( \pm)$ or sometimes weak $(+)$ immunoreactivity for EGF-R in vessel walls. Corpora albicans and intercellular collagen did not react at all (Fig. 1A). A similar staining pattern was observed in the stromal component of most $(34 / 50 ; 68 \%)$ tumor specimens (Fig. 1 B). The immunostaining results of 50 tumors of the various histological subtypes are summarized in Table 1.

Regarding epithelial ovarian tumors, an increased immunoreactivity for EGF-R in tumor cells was noticed in $25 / 46(54 \%)$ of the specimens examined (see Table 1). Staining was intracellular (cytoplasmic) in all cases. Intensity of staining varied from weak $(+)$ to strong $(+++)$ (Fig. 2). The distribution of stained cells appeared heterogeneous, varying from the focal or mosaic type in 18 cases, to the diffuse type in 7 cases. Immunoreactivity was considered negative (not above stroma level) in 21 cases. No clear correlation was found between enhanced expression of EGF-R from the staining pattern, either with respect to the staining intensity (Fig. 2) or to the percentage of positive cells (Fig. 3), and the histological type of the tumor. Regarding the other ovarian tumors examined, apart from one immature teratoma with an evident epithelial component, no clear enhanced expression of EGF-R was noticed in the cells of one gra- 


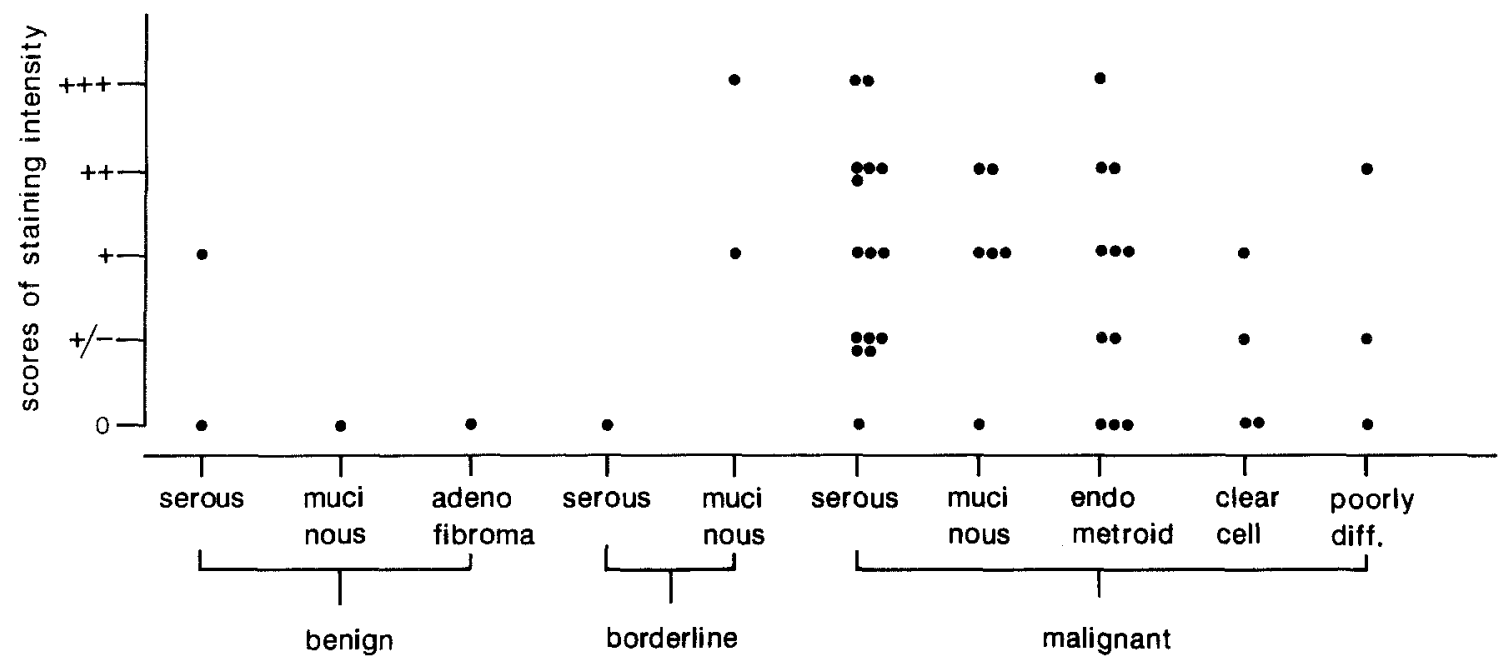

Fig. 2. Scores for intensity of immunostaining for epidermal growth factor receptor (EGF-R) in epithelial ovarian tumors in relation to their histological subtypes. 0 , Negative; \pm , very weak; + , weak; ++ , moderate; +++ , strong positive.,,++++++ were considered as positive $0, \pm$ as negative

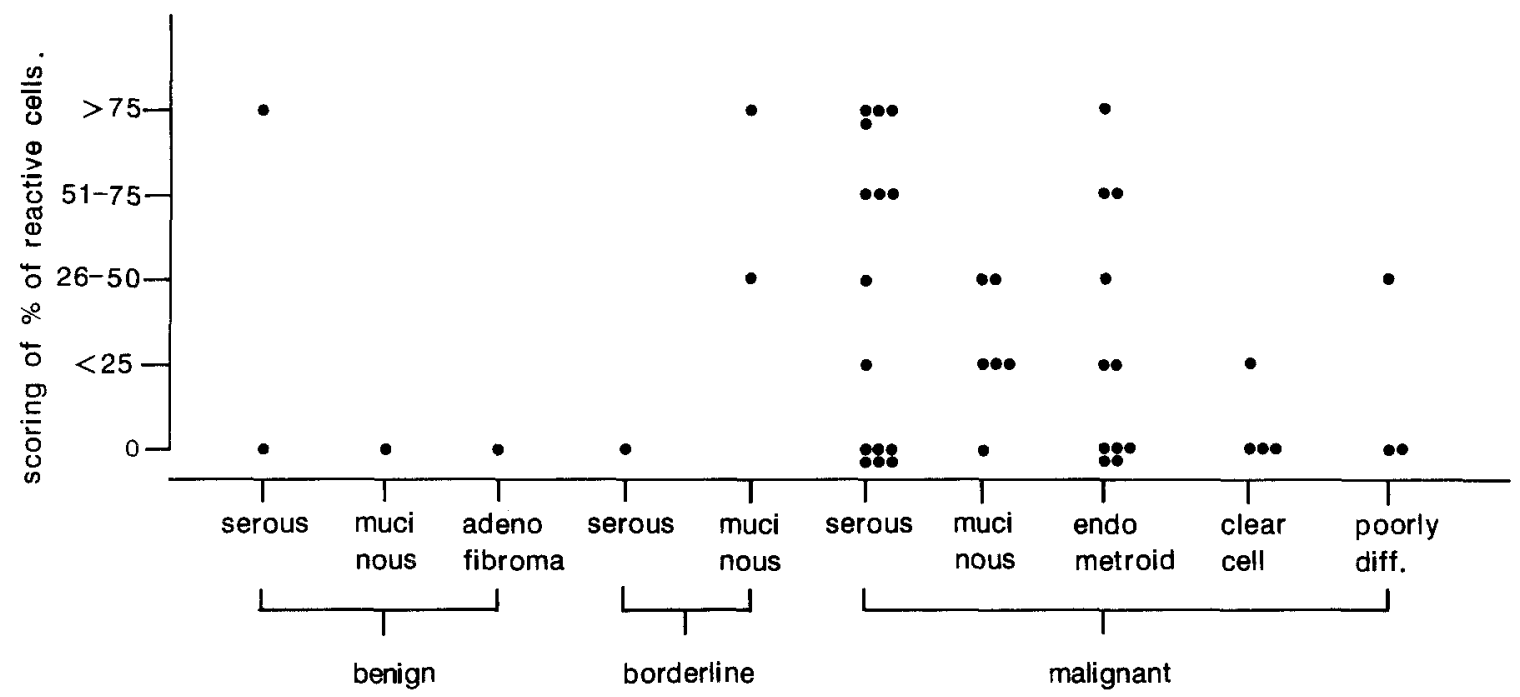

Fig. 3. Scores for percentage of EGF-R-positive epithelial cells in epithelial ovarian tumors. Percentage ranges are shown on the vertical axis; $<25,5 \%-25 \%$

nulosa cell tumor and two thecomas. In 9 tumor specimens necrotic areas were present. In these necrotic areas often $(8 / 9)$ a very weak to weak immunoreactivity was noticed as well.

\section{Discussion}

A number of monoclonal EGF-R antibodies have been raised by various investigators. Some of these react to a carbohydrate determinant that is closely related to the human blood group A antigen. This may be a source of misinterpretation. Since antibody $2 \mathrm{E} 9$ is reactive to the protein core of the EGF-R molecule, cross-reactivity with the blood group A antigen does not occur. In addition, 2E9 has been shown to block binding of EGF to its low-affinity receptor without interfering with EGF binding to its high-affinity receptor (Defize et al. 1989).
In this study we demonstrate the presence of EGF-R in $22 / 39(56 \%)$ adenocarcinomas (Table 1). This incidence is between those indicated by biochemical data, which have been obtained by radioligand-binding assay on membrane homogenates as described by Bauknecht et al. $(1989 \mathrm{a}, \mathrm{b})(45 \%$ EGF-R positivity in 141 ovarian tumors), and Battaglia et al. (1989) (75\% EGF-R positivity in 24 ovarian tumors).

In our study using immunohistochemistry, the positive incidence of EGF-R was not clearly different among the histological subtypes (Figs. 2,3), but some subgroups are relatively small. Bauknecht et al. (1988) reported a positive association of EGF-R activity with endometrioid carcinomas (5/8 EGF-R positive) and a negative association with clear-cell carcinomas (8/8 EGF-R negative). This discrepancy remains at present unclear, but may be due to the different techniques used to assay EGF-R, or to the low number of patients in the various subclasses in both studies. 
Whether or not EGF-R positivity is associated with malignant transformation of epithelial ovarian tumors is difficult to answer. The number of benign and borderline malignant tumors examined in our study is too small to allow any conclusion, and these tumors were not included in the studies of Bauknecht et al. $(1988,1989 a, b)$ and Battaglia et al. (1989).

The cytoplasmic localization of EGF-R, as shown in our study and also reported by others in other types of tissue (Damjanov et al. 1989; Yasui et al. 1988; Nonomura et al. 1988) may reflect internalization of receptor, a rapid process that occurs after ligand binding, but may also represent newly biosynthesized EGF-R molecules within the Golgi that have yet to be processed and inserted into the cell membrane.

A striking finding was the binding of 2E9 to stromal and blood vessel endothelial cells in most "normal" ovaries $(9 / 10)$ and in $34 / 50$ tumor specimens studied. The intensity of stroma staining was very weak $( \pm)$, whereas in endothelial cells of the vessel walls it was very weak \pm to weak $(+)$. Staining of the stroma and vessel walls has also been described by Shiurba et al. (1988) in endothelial cells of meningeomas and by Damjanov et al. (1989) in a variety of normal human tissues. Differences in staining intensity (shown in the study of Shiurba et al. 1988; to slightly above background in the study of Damjanov et al. 1989) may be due to either the different antibodies or the different techniques used. The presence of EGF-R in human fibroblasts has also been reported by Carlin et al. (1982) and Green et al. (1985), as has the presence of EGF-R in endothelial cells (Schreiber et al. 1986; Gospodarowicz et al. 1978; Knedler and Han 1987). It was suggested that EGF may induce proliferation of (human) endothelial cells in vivo (Schreiber et al. 1986) and in vitro (Gospodarowicz et al. 1978; Knedler et al. 1987).

Apart from EGF-R staining of epithelial and stromal cells, necrotic areas may be stained as well. Non-specific immunohistochemical reactivity is common in areas of tissue necrosis. Still the observation is in line with the autoradiographic results of Reubi and Torhorst (1988) in human breast cancer. Therefore, it might be specific after all, possibly indicating the presence of membrane remnants in the necrotic areas.

Both observations may be of importance with respect to the prognostic evaluation of tumors based on EGF-R measurements using biochemical binding assays. The measurement of EGF-R should therefore also be considered using methods allowing clear identification of EGF-R in tumor cells.

The role of EGF-R is still poorly understood in both the normal and the diseased state. As a result of EGF binding there is increased DNA synthesis, and cell proliferation (Gospodarowicz et al. 1983; Bauknecht et al. 1986). Recently it has been reported that extracts of several gynecological malignancies, including ovarian tumors, show growth-promoting activity in vitro and are able to compete with EGF-R (Reubi and Torhorst 1988; Gospodarowicz et al. 1983). In human breast (Sainsbury et al. 1987; Nicholson et al. 1989), bladder (Neal et al. 1985) and stomach cancer (Yasui et al. 1988) EGF-R expression may identify a subclass of more aggressive tu- mors with a high metastatic potential. This would be even more so if EGF and EGF-R are synchronously expressed, suggesting autocrine regulation. The findings of Battaglia et al. (1989) showing higher levels of EGF-R in less differentiated endometroid carcinoma as well as in metastatic ovarian carcinoma support this hypothesis. Bauknecht et al. (1989 b, 1990) suggests a more favorable response to chemotherapy in case of EGF-R positivity in ovarian carcinomas, but there was no effect on survival. The significance of EGF-R in ovarian carcinomas, in a cohort of patients treated in a uniform way according to the stage of the disease, awaits further study. At present we aim to measure EGF-R by both biochemical and immunohistochemical methods in larger series of patients and to correlate the results with each other and with the prognosis.

Acknowledgements. This study has been made possible thanks to the collaboration with the Rotterdam University Hospital, St. Clara Hospital, Maria Hospital Tilburg, Zuider Hospital, Bergweg Hospital, Refaja Hospital Dordrecht, The Lievensberg Bergen op Zoom and Beatrix Hospital Gorinchem, The Netherlands.

\section{References}

Battaglia F, Scambia G, Panici PB, Baiocchi G, Derrone L, Iarobelli S, Mancuso S (1989) Epidermal growth factor receptor expression in gynecological malignancies. Gynecol Obstet Invest 27:42-44

Bauknecht T, Kiechle M, Bauer G, Siebers J (1986) Characterization of growth factors in human ovarian carcinoma. Cancer Res 46:2614-2618

Bauknecht TH, Runge M, Schwall M, Pfleiderer A (1988) Occurrence of epidermal growth factor receptor in human adnexal tumors and their prognostic value in advanced ovarian carcinomas. Gynecol Oncol 28:147-157

Bauknecht T, Janz I, Kohler M, Pfleiderer A (1989a) Human ovarian carcinomas: correlation of malignancy and survival with the expression of epidermal growth factor receptor (EGF-R) and EGF-like factors (EGF-F). Med Oncol Tumor Pharmacother 6:121-127

Bauknecht T, Kohler M, Janz I, Pfleiderer A (1989 b) The occurrence of epidermal growth factor receptors and the characterization of EAF-like factors in human ovarian, endometrial, cervical and breast cancer. J Cancer Res Clin Oncol 115:193-195

Bauknecht T, Birmelin G, Konnoss F (1990) Clinical significance of oncogenes and growth factors in ovarian carcinomas. J Steroid Biochem Mol Biol 37:855-862

Carlin CR, Philips PD, Knowles BB (1982) Diminished in vitro tyrosine kinase activity of the EGF receptor of senescent human fibroblasts. Nature 306:617

Damjanov I, Mildner B, Knowles BB (1989) Immunohistochemical localization of the epidermal growth factor receptor in normal human tissue. Lab Invest 55:588-592

Defize LHK, Mummery CL, Moolenaar WH, Laat SW de (1987) Antireceptor antobodies in the study of EGF-receptor interaction. Cell Differ 20:87-102

Defize LHK, Boonstra J, Meisenkelder J, Kruyer W, Tertoolen LGJ, Tilly BC, Hunter T, Bergen en Henegouwen PMP van, Moolenaar WH, Laat SW de (1989) Signal transduction by epidermal growth factor occurs through the subclass of high affinity receptors. Cell Biol 109:2495-2507

Foekens JA, Portengen H, Putten WLJ van, Trapman AMA, Reubi JC, Alexieva-Figusch J, Klijn JGM (1989) Prognostic value of receptors for insulin-like growth factor-1, somatostatin, and epidermal growth factor in human breast cancer. Cancer Res 49:7002-7009 
Gospodarowicz D (1983) Growth factors and action in vivo and in vitro. J Pathol 141:201-233

Gospodarowicz D, Brown KD, Birdwell CR (1978) Control of proliferation of human vascular endothelial cells. Characterization of the response of human umbilical vein endothelial cells to fibroblasts growth factor epidermal growth factor and thrombin. J Cell Biol 77:744-788

Green MR, Couchnan JR (1985) Differences in human skin between epidermal growth factor receptor distribution detected by EGF binding and monoclonal antibody recognition. J Invest Dermatol 85:239

Greig R, Dummington D, Murthy U, Anzano M (1988) Growth factors as novel therapeutic targets in neoplastic disease. Cancer Surv 7:404

Knedler A, Han RG (1987) Optimized medium for clonal growth of human microvascular endothelial cells with minimal serum. In Vitro Cell Dev Biol 23:481-491

Neal DE, Marsh C, Bennett MK, Abel PP, Hall RR, Sainsbury JCR, Harris AL (1985) Epidermal growth factor receptors in human bladder cancer: comparison of invasive and superficial tumors. Lancet I:346-348

Neyt JP, Ten Bokkel Huinink WW, Burg MEL van den, Oosterom AT van, Vriesendorp R (1985) Randomized trial comparing two combination regimens (MexaCAF versus CHAP-5) in advanced ovarian cancer. Lancet II:594-600

Nicholson S, Halcrow P, Farndon JP, Sainsbury JRC, Chambers P, Harris AL (1989) Expression of epidermal growth factor receptors associated with lack of response to endocrine therapy in recurrent breast cancer. Lancet I:182-184
Nonomura A, Ohte G, Nakanuma Y, Izumi R, Mizukami Y, Fugitsugu M, Hayashi M, Watanabe K, Takayanagi N (1988) Simultaneous detection of epidermal growth factor (EGF) and ras p21 in cholangiocarcinoma by an immunocytochemical method. Liver 8:157-166

Reubi JC, Torhorst J (1988) EGF receptors in human breast cancer on viable and necrotic tumour cells. Breast Cancer Res Treat 12:245-246

Sainsbury JR, Needmah GH, Farndon JR, Malcolm AJ, Harris AC (1987) Epidermal growth factor receptor status as predictor of early recurrence of and death from breast cancer. Lancet II:1398-1402

Schreiber AB, Winkler MF, Derynck R (1986) Transforming growth factor a. A more potent angiogenic mediator than epidermal growth factor. Science 222:1250-1253

Serov SF, Scully RE (1973) Histological typing of ovarian tumors: international classification of tumours, WHO Offset Publ 9

Shiurba RA, Lawrence F, Vogel H, Lee YL, Horoupian DS, Urich $H$ (1988) Epidermal growth factor receptor in meningioma is expressed predominantly on endothelial cells. Cancer 62:2139 2144

Sutton GD, Stehman FB, Einhorn LH (1989) Ten-year follow-up of patients receiving cisplatin, doxorubicin and cyclophosphamide chemotherapy for advanced epithelial ovarian carcinoma. J Clin Oncol 7:223-229

Yasui W, Hata J, Yokozaki N, Hakatani H, Ochiai A, Ito H, Tahara $E$ (1988) Interaction between epidermal growth factor and its receptor in progression of human gastric carcinoma. Int $\mathbf{J}$ Cancer 41:211-217 